\title{
Recto-Vaginal Pouch
}

National Cancer Institute

\section{Source}

National Cancer Institute. Recto-Vaginal Pouch. NCI Thesaurus. Code C33447.

The peritoneal reflection of the superior part of the posterior wall of the vagina, anterior to the rectum, which is the deepest point of the peritoneal cavity in females. 